\title{
Measurement of Exposure to Black Carbon and Heavy Metals on Cycle Paths in Semarang City
}

\author{
Bambang Priyono ${ }^{1}$, Agung Wahyudi ${ }^{2}$, Mustafa Daru Affandi ${ }^{3}$, Efa Nugroho ${ }^{4}$ \\ \{bambangpriyono@mail.unnes.ac.id ${ }^{1}$, agungwahyudi@mail.unnes.ac.id ${ }^{2}$, da- \\ ru.affandi@mail.unnes.ac.id $\left.{ }^{3}\right\}$ \\ Universitas Negeri Semarang, Semarang, Indonesia ${ }^{1,2,3,4}$
}

\begin{abstract}
Cycling is very popular regardless of age from young to old and even children. The number of cyclists increased during the COVID-19 pandemic. There is no Open Sport Space or a special lane that causes the participants to choose the highway as the route. Besides being at risk of accidents, they are also vulnerable to traffic air pollutants or the traffic-related air pollutants (TRAP). The TRAP components are Carbon Black (BC), Nitrogen Dioxide (NO2), Ultrafine Particles (UFPs), and Heavy Metals. TRAP is dangerous for health. The purpose of this study was to determine the level of pollutants on the highway that was passed by cyclists. This research was experimental research. The population and research sample was Semarang City Highway and cyclist comunity. The results of this study showed that the levels of pollutants during the COVID-19 pandemic were lower when compared to normal days.
\end{abstract}

Keywords: Exposure, Pollutant, Cyclist.

\section{Introduction}

The phenomenon of sports culture in the community is believed to be not merely a health-supporting activity, but also a support for social needs in which health, psychological, and socio-cultural fitness values can be attached. Sport can make a real valuable contribution and inspire human well-being and survival from physical, spiritual and social aspects. The meaning contained in sports activities is not just physical education and achievement, but more broadly related to overall goals, and can contribute to life for each individual in physical, mental and social aspects. The sport that is currently favored by the public right now is cycling.

Cycling is now a trend among the people, in addition to running. Some even think that besides being used as a transportation and sports suggestion, cycling is also a lifestyle. $\mathrm{Cy}-$ cling is very popular regardless of age from young to old and even children. We have now met many workers who are cycling to go to the office and also elementary school students to students who are cycling to their respective destinations.

To be able to carry out sports activities optimally, sports facilities and infrastructure are needed, including open spaces that can be accessed to exercise so that they can move freely 
without any obstacles. Open space in sports (OSS) is a basic requirement for sports activities. Without adequate and narrow open spaces it is difficult to expect community participation in sports activities. The more public sports facilities and infrastructure available, the easier it is for people to use and use them for sports activities. Conversely, the more limited public sports facilities and infrastructure available, the more limited the opportunity for people to use and utilize them for sports activities. Thus, the availability of public sports facilities and infrastructure will affect the level and pattern of community participation in sports.

Cycling is a recreational or sports activity, and is one of the modes of land transportation that uses bicycles. The bike was first introduced in the 19th century AD. Many cycling enthusiasts who carry out these activities in various fields, such as hills, steep terrain or just rural and urban areas. People who use bicycles as a routine mode of transportation can also be called commuters. The use of bicycles as a mode of routine transportation is not only done by workers who work in the informal sector, but also is done by workers who work in the formal sector.

The number of cyclists is now increasingly found on the streets. In other words, this relaxed but healthy exercise is increasingly in demand. The cyclist community is also increasing now.

But cyclists rarely pay attention to the health risks that can arise if they carry out their hobbies in places where air pollution is high. Unwittingly the dirty air we breathe every day, can be very dangerous for health. Yet according to WHO, currently 9 out of 10 people breathe in polluted air. The impact of air pollution has also killed around 7 million people each year.

Increased interest in cycling in the city of Semarang is not matched by an increase in supporting facilities and infrastructure. The absence of Open Space Sports (OSS) or special lanes causes the participants to choose the highway as the route. Besides being at risk of accidents, they are also vulnerable to exposure to air pollutants due to traffic or the term traffic-related air pollutants (TRAP). The TRAP components include Carbon Black (BC), Nitrogen Dioxide (NO2), Ultrafin Particles (UFPs), and Heavy Metals. TRAP is dangerous for health. TRAP has been linked to several adverse health outcomes including increased asthma, cardiovascular risk, risk of lung cancer, fatal myocardial infarction, and increased mortality. TRAP is a silent killer because of its physical nature which is tasteless, colorless, and odorless, but in high concentrations can cause death in humans who are exposed quickly.

A study on TRAP exposure for cyclists in Semarang City is needed so that efforts to mitigate exposure to air pollution for cyclists can be carried out. The purpose of this study is to determine the Exposure of Black Carbon, Ultrafin Particles, and Heavy Metals in the Cycling Community.

\section{$2 \quad$ Method}

This research is an experimental research with one group pretest post test design. The population and sample of the study are Semarang City Cyclists Community.

The study was carried out by measuring pollutants on the routes that cyclists traveled and exposure to pollutants on cyclists. Because of the high temporal variability of TRAP that is measured, monitoring can only be considered representative if the data series is large. 
In our study, walking monitoring per week (according to the cycling schedule) was carried out along the route of travel. For each route 8 repetitions are performed, between 6/1/2020 and $3 / 23 / 2020$. To consider the effects of road congestion and looseness, the route changes every week. The average cycling speed is $20 \mathrm{~km} /$ hour. Also installed a heart rate measuring device.

\section{$3 \quad$ Results and discussions}

The level of atmospheric pollution in a heterogeneous and typical urban environment can be known to vary greatly in space and time. While spatial variation is the main association with differences in traffic intensity, urban topology and distance to individual pollutant sources, temporal variations consist of day to day (mainly meteorological fluctuations and urban backgrounds), daily conditions (mainly due to traffic dynamics) and scale variations micro (short-term single event) [1].

Because the traditional stationary air quality monitoring network is limited in terms of spatial coverage, cellular monitoring devices, the possibility of personalized monitoring and high resolution, has become increasingly popular over the past decade [2-4]. Especially for atmospheric pollutants that experience large temporal spatial variations in urban environments. Cellular monitoring provides valuable insights into the range of atmospheric pollution faced by city dwellers in daily life, and the potential for this to occur in the local area which, as a result, can be targeted by policy makers and urban planning planners $[5,6]$.

Table 1. Recap of CO level measurement

\begin{tabular}{rlrrrrrrr}
\hline \multirow{2}{*}{ No } & \multirow{2}{*}{ Location } & \multicolumn{3}{c}{ Data read $(\mathrm{ppm})$} & \multicolumn{3}{c}{ Average } \\
\cline { 3 - 7 } & & 1 & 2 & 3 & 4 & 5 & 16,2 \\
1 & Simpang Lima & 16 & 15 & 18 & 16 & 16 & 14 \\
2 & Pertigaan Thamrin & 14 & 14 & 13 & 15 & 14 & 14,4 \\
3 & Tugumuda & 14 & 13 & 12 & 16 & 17 & 11,4 \\
4 & Perempatan Petompon & 12 & 11 & 12 & 12 & 10 & \\
\hline
\end{tabular}

As with walking, cyclist exposure is also quite a contentious issue, with research providing conflicting results. Studies found CO levels to be substantially lower than cars, and lower than pedestrians during most sampling instances Later research confirmed the contrary, with cyclists receiving higher levels than walk, car and bus.

Nevertheless, there are various potential factors influencing cyclist exposure. These include: position on the road; traffic light timings; ability to pass between congested traffic; height of cyclist from ground; chosen route; traffic density and use of bus or cyclist lanes. In a journal entitled "Personal exposure to Black Carbon in transport microenvironments", the results showed $6 \%$ of the time spent in transportation but contributed to carbon black exposure to the body by $21 \%$ [7]. The concentration of carbon black in transportation is 2-5 times higher than its concentration in the home. The highest exposure to black carbon uses bus, motorcycle and car transportation while the lowest uses train. Exposure by cycling or walking in busy traffic also results in high exposure, whereas using bicycles in a quiet or rural area receives low carbon black exposure. For the use of a car at work activities receive higher carbon black exposure than using a car for recreational activities. The highest dose of 
carbon black inhalation occurs when cycling or walking casually on a highway or urban road.

Table 2. Recap of PM 10 dust measurement

\begin{tabular}{lllllllll}
\hline No & Location & $\begin{array}{l}\text { Time } \\
(\text { Min })\end{array}$ & $\begin{array}{l}\text { Air Flow } \\
(1 / \mathrm{m})\end{array}$ & $\begin{array}{l}\text { Air Volume } \\
(\mathrm{m} 3)\end{array}$ & $\begin{array}{l}\text { Weig } \\
\mathrm{ht} 2\end{array}$ & $\begin{array}{l}\text { Weig } \\
\mathrm{ht} 1\end{array}$ & $\begin{array}{l}\text { Dust } \\
\text { Weigh } \\
\mathrm{t}\end{array}$ & $\begin{array}{l}\text { Dust Conc } \\
(\mathrm{MG} / \mathrm{m} 3)\end{array}$ \\
\hline 1 & $\begin{array}{l}\text { Simpang } \\
\text { lima }\end{array}$ & 60 & 750 & 45 & 5122 & 4720 & 402 & 8,933333333 \\
2 & 60 & 700 & 42 & 5104 & 4940 & 164 & 3,904761905 \\
& $\begin{array}{l}\text { pertigaan } \\
\text { thamrin }\end{array}$ & & & & & & & \\
3 & $\begin{array}{l}\text { tugumuda } \\
\text { perempatan } \\
\text { petompon }\end{array}$ & 60 & 750 & 45 & 5098 & 4855 & 243 & 5,4 \\
\hline
\end{tabular}

Jelle Hofman et al (2018), with the title "Cyclist exposure to black carbon, ultrafine particles and heavy metals: An experimental study along two commuting routes near Antwerp, Belgium". The results showed that the average black carbon was $300 \%$ and ultrafin particles were $20 \%$ higher in the traffic lane than in the bicycle lane (vehicle free) [8]. This research shows that cyclists who wish to reduce their exposure to black carbon, ultrafin particles and heavy metals must choose lane routes with fewer vehicles or busy lanes.

The exposure of carbon black on the main (busy) line was very high especially at the crossroads, where many machines stopped. This exposure is greatly reduced when cyclists pass alternative route routes that do not have many vehicles and do not have many intersections. Measurements in the urban environment, influenced by traffic and biomass burning, show that air pollution of the main traffic, and carbon black in particular, has a significant impact on cyclist exposure. The results imply that cycling route planning must aim for greater distances between cycling routes and motorized traffic, must consider the number of intersections and consider at the same time the exchange / distance.

Table 3. Recap of the results of lung phalms measurement

\begin{tabular}{|c|c|c|c|c|c|c|c|c|}
\hline No & Name & Gender & Age & FVC & FEV1 & FEV1/FVC \% & PEF & Information \\
\hline 1 & Asti & $\mathrm{F}$ & 29 & 86 & 88 & 104 & 73 & Normal Spirometry \\
\hline 2 & Budi & M & 36 & 93 & 87 & 98 & 62 & Normal Spirometry \\
\hline 3 & Choirul & M & 30 & 94 & 96 & 104 & 71 & Normal Spirometry \\
\hline 4 & Ramlan & M & 69 & 100 & 115 & 119 & 81 & Normal Spirometry \\
\hline 5 & $\begin{array}{l}\text { Sigal- } \\
\text { ingging }\end{array}$ & M & 37 & 134 & 106 & 83 & 76 & Normal Spirometry \\
\hline 6 & Suryadi & M & 58 & 86 & 97 & 93 & 84 & Normal Spirometry \\
\hline 7 & Tatang & M & 65 & 92 & 112 & 125 & 135 & Normal Spirometry \\
\hline
\end{tabular}


The effect of environmental control on CO levels and dust on shows that age has no influence on road exposure which can cause lung disorders. Statistical results showed that there was no significant difference between sex and lung function ( $p>0.05)$. Statistical results between years of service and pulmonary function did not show a significant difference ( $p>0.05$ ). Based on exercise habits, exercise generally can increase lung capacity. Individuals who do regular exercise lung capacity will increase. The conclusion is that there is no significant difference between age, and sex, on lung capacity. However, there is a relationship between exercise habits and lung function.

\section{Conclusions}

The results of this study showed that the levels of pollutants during the COVID-19 pandemic were lower when compared to normal days. But that does not mean harmless to cyclists. There is no significant difference between age, and sex, on lung capacity. However, there is a relationship between exercise habits and lung function.

For the next stop of research is measuring exposure to pollutants in cyclists on the highway.

\section{References}

[1] Pattinson WJ. Cyclist Exposure To Traffic Pollution: Microscale Variance, The Impact Of Route Choice And Comparisons To Other Modal Choices In Two New Zealand Cities. Christchurch: University of Caterbury; 2009.

[2] Gulliver J, Briggs D. Journey-time exposure to particulate air pollution. Atmos. Environ. 2007; 41:7195-7207.

[3] Berghmans P, Bleux N, Panis LI, Mishra VK, Torfs R, Van Poppel M. Exposure assessment of a cyclist to PM10 and ultrafine particles. Sci. Total Environ. 2009; 407(4): 1286-1298.

[4] Adams HS, Nieuwenhuijse, MJ, Colvile RN, Older MJ, Kendall M. Assessment of road users elemental carbon personal exposure levels, London, UK., Atmos. Environ. 2002; 36(34):53355342.

[5] Boogaard H, Borgman F, Kamminga J, Hoek G. Exposure to ultrafine and fine particles and noise during cycling and driving in 11 Dutch cities. Atmos. Environ. 2009; 43(27):4234-4242.

[6] Brunekreef B, Holgate ST. Air pollution and health. The Lancet. 2002; 360(9341): 1233-1242.

[7] Dons E, Panis LI, Poppel M, Theunis J, Wets G. Personal exposure to Black Carbon in transport microenvironments. Atmos. Environ. 2012; 55:392-398.

[8] Jelle H, Roeland S, Steven J, Ronny B, Silvia L. Cyclist exposure to black carbon, ultrafine particles and heavy metals: An experimental study along two commuting routes near Antwerp, Belgium Environmental Research. Environ. Res. 2018; 164:530-538. 